\title{
The Study of Burden of Family Caregivers of Patients Living with Psychiatric Disorders in Remote Area of Nepal Kunwar D, ${ }^{1}$ Lamichhane $S,{ }^{2}$ Pradhan $N,{ }^{1}$ Shrestha B, ${ }^{1}$ Khadka $S,{ }^{1}$ Gautam K, ${ }^{2}$ Risal ${ }^{1}$
}

${ }^{1}$ Department of Psychiatry

Dhulikhel Hospital, Kathmandu University Hospital Kathmandu University School of Medical Sciences Dhulikhel, Kavre, Nepal.

${ }^{2}$ Medical Officer,

Ministry of Health

Kathmandu, Nepal.

\section{Corresponding Author}

Dipak Kunwar

Department of Psychiatry

Dhulikhel Hospital, Kathmandu University Hospital Kathmandu University School of Medical Sciences Dhulikhel, Kavre, Nepal.

E-mail: drdipak.kunwar@gmail.com

\section{Citation}

Kunwar D, Lamichhane S, Pradhan N, Shrestha B, Khadka S, Gautam K, Risal A. The Study of Burden of Family Caregivers of Patients Living with Psychiatric Disorders in Remote Area of Nepal. Kathmandu Univ Med J. Online First.

\section{ABSTRACT}

\section{Background}

Family caregivers of psychiatric disorders likely to face burden. There is a paucity of data regarding the caregiver burden in psychiatric disorders in context of Nepal.

\section{Objective}

To study the caregiver burden in families with psychiatric illness and to find association between socio-demographic variables and caregiver burden in families with psychiatric illness.

\section{Method}

This is an analytical cross-sectional study. The participants $(n=96)$ were caregiver of patients visiting outpatient department of two government of Nepal primary health care centers namely, Panchkhal Primary Health Care Center (PHC) Kavre District and Barhabise Health Care Center Sindhupalchowk district. The sample size has been determined by using statistical formula. Family burden assessment schedule (FBIS) was used for the study.

\section{Result}

The majority of the caregivers were females $56.3 \%$. Most of the caregivers were aged below 45 years $54.2 \%$. The large number of participants were single or separated $74 \%$. The mean score of family burden assessment schedule was $27 \pm 9.8$ (range 0 to 48) with positive rate of $59.4 \%$.Among the objective burden domains disruption of family leisure $61.5 \%$ was the most frequently reported burden. The subjective burden was reported in $95 \%$. There were significant differential demographic associations with different domains of caregivers' burden.

\section{Conclusion}

Caregivers of Psychiatric patients experience different kind of burden of care. Our findings highlight the support to the family members to reduce their burden.

\section{KEY WORDS}

Caregivers, Burden, Mental disorder, Nepal 


\section{INTRODUCTION}

Family caregiver refers to any unpaid individuals such as family, friends, relatives, neighbors who render help to the individuals who need it. ${ }^{1}$ The term "caregiver burden" implies to the effects on physical, emotional and financial aspects of caregivers life. ${ }^{2}$ Shift from institution based to community based care for mental disorders has put a burden on the caregivers of mentally ill patients. ${ }^{3}$ The caregivers are not well prepared to look after mental ill patients at home. As a result, there is a higher prevalence of minor psychiatric disorders in the caregivers of a mentally ill person. ${ }^{4}$ Caregivers for chronically ill disease have reported a greater overload and tend to have taken poorer care of themselves. ${ }^{5}$ Living conditions and environments that support mental health play a key role in promotion of mental health. ${ }^{6}$ The caregiver burden in mental illness can be subjective and objective. ${ }^{7,8}$

The caregiver burden is a global issue. ${ }^{9}$ Several factors are associated with caregiver burden such as having another member in family who needs care. ${ }^{10} \mathrm{~A}$ study done in Iran and Pakistan reported that the burden experienced by women was more than that experienced by men, caregivers had higher burden when the duration of illness of patients was longer and the burden was more in schizophrenia than in mood disorders. ${ }^{11}$ A study done in Nepal, reported $50 \%$ prevalence of caregiver stress in family with mental. ${ }^{12}$ Another study conducted in Nepal, showed that $48.2 \%$ of caregiver experienced moderate burden and $32.1 \%$ had severe burden. ${ }^{13}$ There are very few studies has been done in Nepal so we have planned to study the burden on family of caregivers of psychiatric pateints.

\section{METHODS}

This is an analytical cross-sectional study. The participants are caregiver of patients visiting outpatient department of two government of Nepal primary health care centers namely, Panchkhal Primary Health Care Center (PHC) Kavre District and Barhabise Health Care Center Sindhupalchowk district.

The sample size has been determined by using statistical formula,

$\mathrm{n}=\left(\mathrm{Z}_{\alpha / 2}\right)^{2} \cdot \mathrm{p} \cdot \mathrm{q} / \mathrm{d}^{\wedge} 2$

where,

$Z_{\alpha / 2}=(1.96 / 0.05)$, considering 95\% confidence interval.

$p=$ prevalence of caregiver burden( 50\% Prevalence)(12)

$q=1-p$

$d=10 \%$

The minimum sample size has come to be 96 . The study was initiated after receiving approval from the Institutional
Review Committee (IRC), Kathmandu University School of Medical Sciences (KUSMS). Informed consent was obtained and those who were willing to participate and who were providing care of patients diagnosed with psychiatric disorders were included in the study anf those who were giving care for less than one month has been excluded.

We designed a questionnaire focusing on sociodemographic profile of caregiver. The questions concerned: age, marital status, working status, education, living with patient or not, relation of caregiver with patients, duration of care, type of mental lines in the family member and personal history of psychiatric illness.

In our study we used Pai and Kapoor's Family Burden Interview Schedule for the assessment of family burden. This scale consists of twenty four items arranged into six different categories: 1. Financial burden 2. Disruption of routine family activities. 3. Family leisure. 4. Family interactions. 5. Effect on physical health of others and 6.Effect on mental health of others.

Each item is scored as absent (score 0 ), moderate (Score 1 ) and Severe (Score 2).

The $25^{\text {th }}$ question is the qualitative question assessing the subjective burden ( 1 item).

The total objective score of FBIS ranges from 0 to 48 , the higherscores indicates higher burden.

A mean score of FBIS is obtained by dividing the total score of FBIS by the number of Items, with a positive result defined as a mean score of $\geq 1$, indicating moderate and Severe burden.

Statistical analysis was done in SPSS 21.0 (SPSS Inc, Chicago, USA). variables were expressed in terms of mean and standard deviation (SD) Chi-square test was done for comparision of variables. $P$ value of less than 0.05 was considered statistically significant.

\section{RESULTS}

The socio demographic details of patients were shown in table 1 . The total sample size was 96 , majority of the caregivers were females $(n=54)$. Most of the caregivers were aged below 45 years $(n=52)$. The large number of participants were single or separated $(n=71)$. Majority of caregivers $(n=71)$ were close relatives (spouse, children, parents) and majority ( $n=92$ ) used to live with the patients.

Table 2 presents the level and domains of family burden. The mean score of family burden assessment schedule (FBIS) was $27 \pm 9.8$ (range 0 to 48 ) with positive rate of $59.4 \%$. Among the objective burden domains disruption of family leisure $61.5 \%$ was the most frequently reported burden. When it comes to the subjective burden 35\% reported moderateburden and 60\% reported severe burden (table 3). 
Table 1. Sociodemographic Details of Caregivers and Total Objective Burden ( $n=96$ )

\begin{tabular}{|c|c|c|}
\hline Variables (caregivers) & Frequency (\%) & $\begin{array}{l}\text { Total Objective } \\
\text { burden score } \\
\text { Mean (SD) }\end{array}$ \\
\hline \multicolumn{3}{|l|}{ Age(years) } \\
\hline Up to 45 & $52(54.2)$ & $24.6(9.8)$ \\
\hline 45 and above & $44(45.8)$ & $27.4(10.4)$ \\
\hline \multicolumn{3}{|l|}{ Sex } \\
\hline Male & $42(43.8)$ & $26.2(11.8)$ \\
\hline Female & $54(56.3)$ & $25.7(8.8)$ \\
\hline \multicolumn{3}{|l|}{ Marital status } \\
\hline Married and Co-habitating & $25(26)$ & $23.7(10.3)$ \\
\hline Single and Separated & $71(74)$ & $26.7(10.1)$ \\
\hline \multicolumn{3}{|l|}{ Educational level } \\
\hline No formal education & $32(33.3)$ & 23.2(11.9) \\
\hline Formal education & 64(66.7) & $27.2(9.0)$ \\
\hline \multicolumn{3}{|l|}{ Main work status } \\
\hline Paid work & $28(29.2)$ & $25.5(10.6)$ \\
\hline $\begin{array}{l}\text { Unpaid work(student, house } \\
\text { wife, retired) }\end{array}$ & $68(70.8)$ & $26.0(10.0)$ \\
\hline \multicolumn{3}{|l|}{ Family income (monthly) } \\
\hline Up to 10000 & $41(42.7)$ & $25.8(11.0)$ \\
\hline 10000 and above & $55(57.3)$ & $25.9(9.6)$ \\
\hline \multicolumn{3}{|l|}{ Duration of care } \\
\hline Up to 5years & $52(54.2)$ & $24.5(10.2)$ \\
\hline 5 years and above & $44(45.8)$ & $27.5(10.0)$ \\
\hline \multicolumn{3}{|c|}{ Relationship of caregiver with patients } \\
\hline Close & $71(74)$ & $26.3(9.9)$ \\
\hline Not close & $25(26)$ & $24.6(11.0)$ \\
\hline \multicolumn{3}{|l|}{ Living with patients } \\
\hline Yes & $92(95.8)$ & $26.0(10.3)$ \\
\hline No & $4(4.8)$ & $24.2(7.5)$ \\
\hline
\end{tabular}

Demographic and socio psychological factors and its association with family burden domains were presented in table 4. Age, sex, marital status, educational status working status, monthly income, duration of care relationship with the patients of the caregivers all are associated ( $p$ value $<$ 0.05 ) with different domains of family burdens.

\section{DISCUSSION}

The positive rate of burden in this study was $59.4 \%$ which was less than the other studies done in Nepal. Sharma et al. showed $85 \%$ burden and Bhandari et al. showed $80.3 \%$ burden among caregivers. ${ }^{13,14}$

Our study showed total objective burden score FBIS $27 \pm$ 9.8 which was comparable with Koujali et al. study from India. ${ }^{15}$ The mean burden score in our study was higher than that reported in Lasebikan et al. study of a Nigeria sample (22.69 \pm 6.21$)$, Thomas et al. study of another Indian sample (21.74 \pm 7.50$)$ and Chan et al. study in a Hongkong
Table 2. Level and Domains of Objective Family Burden $(n=96)$

\begin{tabular}{|lll|}
\hline Burden domains & $\begin{array}{l}\text { Mean score } \\
\text { (SD) }\end{array}$ & $\begin{array}{l}\text { Positive } \\
\text { burden \% }\end{array}$ \\
\hline Objective Burden & $27.0(9.8)$ & 59.4 \\
\hline Financial burden & $7.7(2.5)$ & 36.5 \\
\hline Disruption of routine family activities & $5.5(2.4)$ & 38.5 \\
\hline Disruption of family leisure & $4.3(2.0)$ & 61.5 \\
\hline Disruption of family interactions & $4.1(2.6)$ & 43.8 \\
\hline Effect on physical health of others & $2.0(1.7)$ & 34.4 \\
\hline Effect on mental health of others & $1.8(2.1)$ & 31.3 \\
\hline
\end{tabular}

Table 3. Frequency Subjective Family Burden ( $n=96)$

\begin{tabular}{|ll|}
\hline Burdens & $\mathbf{N}(\%)$ \\
\hline No burden & $4(4.2)$ \\
\hline Moderate burden & $34(35.4)$ \\
\hline Severe burden & $58(60.4)$ \\
\hline
\end{tabular}

sample $(15.75 \pm 9.27 / 12.54 \pm 8.43) .{ }^{16-18}$ however our score from our study was very less as compared to Fallahi et al. study from Iran. ${ }^{19}$

The different findings could be due to different assessment tools used by different authors. In our study the mean burden score in the financial domain $7.7 \pm 2.5$ and disruption of routine family activities $5.5 \pm 2.4$, were comparable with financial burden score of $6.86 \pm 2.44$ and disruption of family routine activities score of $4.88 \pm 1.64$ findings of Hidru et al. ${ }^{20}$

Other domains findings from our study Disruption of family leisure $4.3 \pm 2.03$, disruption of family interactions $4.1 \pm$ 2.6, effect on physical health of others $2.0 \pm 1.7$, effect on mental health of others $1.8 \pm 2.1$ were also consistent with findings from the study done by Lasebikan et al. which shows Disruption of family leisure $4.74 \pm 2.03$, disruption of family interactions $4.42 \pm 1.83$, effect on physical health of others $1.32 \pm 0.72$, effect on mental health of others 0.99 $\pm 0.39 .^{16}$

Our study reported $95.8 \%$ caregiver's subjective burden which was also supported by the study conducted by Hailemariam et al. ${ }^{21,22}$

Our study reported older age group experienced highly significant burden in the area of phyical health of others ( $p$ 0.001) and family leisure ( $p$ 0.01). This finding might be, the medical conditions are more prevalent in older population. ${ }^{23}$

Other significant factors that were associated with caregivers' burden were: sex in the domain of financial burden $p$ value 0.01 , single and seperated in the domain of financial burden $p$ value 0.03 , education in the domain of family leisure $p$ value 0.03 , working status in the domain of family interaction $p$ value 0.03 , relationship with patients, duration of care and monthly income in domain of financial burden $p$ value $0.04,0.003$ and 0.03 
Table 4. Association between different variables and family burden domains $(n=96)$

\begin{tabular}{|c|c|c|c|c|c|c|c|}
\hline variables & Financial & $\begin{array}{l}\text { Routine } \\
\text { activities }\end{array}$ & Family leisure & $\begin{array}{l}\text { Family } \\
\text { interaction }\end{array}$ & $\begin{array}{l}\text { Effect on } \\
\text { Physical health }\end{array}$ & $\begin{array}{l}\text { Effect on Mental } \\
\text { health }\end{array}$ & $\begin{array}{l}\text { Total objective } \\
\text { burden }\end{array}$ \\
\hline & Yes & Yes & Yes & Yes & Yes & Yes & Yes \\
\hline & N (\%) & N (\%) & N (\%) & N (\%) & N (\%) & N (\%) & N (\%) \\
\hline \multicolumn{8}{|l|}{ Age } \\
\hline Up to 45 & $16(45.7)$ & $16(43.2)$ & $26(42.4)$ & $18(42.9)$ & $10(30.3)$ & $12(40)$ & $49(53.3)$ \\
\hline 45 and above & $19(54.3)$ & $21(56.8)$ & $33(55.9)$ & $24(57.1)$ & $23(69.7)$ & $18(60)$ & $43(46.7)$ \\
\hline$x^{2}$ & 1.6 & 2.9 & 6.2 & 3.84 & 11.5 & 3.5 & 0.73 \\
\hline df & 1 & 1 & 1 & 1 & 1 & 1 & 1 \\
\hline $\mathbf{p}$ & 0.20 & 0.08 & 0.01 & 0.05 & 0.001 & 0.06 & 0.39 \\
\hline \multicolumn{8}{|l|}{ Sex } \\
\hline Male & $21(60)$ & $18(48.6)$ & $25(42.4)$ & $17(40.5)$ & $15(45.5)$ & $14(46.7)$ & $39(42.4)$ \\
\hline Female & $14(40)$ & $19(51.4)$ & $34(57.6)$ & $25(59.5)$ & $18(54.5)$ & $16(53.3)$ & $53(57.6)$ \\
\hline$x^{2}$ & 5.9 & 0.58 & 0.11 & 0.32 & 0.05 & 0.15 & 1.65 \\
\hline df & 1 & 1 & 1 & 1 & 1 & 1 & 1 \\
\hline $\mathbf{p}$ & 0.01 & 0.44 & 0.73 & 0.57 & 0.80 & 0.69 & 0.19 \\
\hline \multicolumn{8}{|l|}{ Marital status } \\
\hline Married and cohabitating & $12(34.4)$ & $10(27.0)$ & $12(20.3)$ & $8(19)$ & $6(18.2)$ & $7(23.3)$ & $22(23.9)$ \\
\hline Single/separated & $23(65.7)$ & $27(73.0)$ & $47(79.7)$ & $34(81)$ & $27(81.8)$ & $23(76.7)$ & $70(76.1)$ \\
\hline$\chi^{2}$ & 2.0 & 0.03 & 2.5 & 1.9 & 1.6 & 0.16 & 5.19 \\
\hline df & 1 & 1 & 1 & 1 & 1 & 1 & 1 \\
\hline $\mathbf{p}$ & 0.16 & 0.86 & 0.10 & 0.16 & 0.20 & 0.63 & 0.02 \\
\hline \multicolumn{8}{|l|}{ Education status } \\
\hline No formal & $10(28.6)$ & $11(29.7)$ & $15(25.4)$ & $12(28.6)$ & $9(27.3)$ & $8(26.7)$ & $30(32.6)$ \\
\hline Formal & $25(71.4)$ & $26(70.3)$ & $44(74.6)$ & $30(71.4)$ & $24(72.7)$ & $22(73.7)$ & $62(67.4)$ \\
\hline$x^{2}$ & 0.56 & 0.35 & 4.3 & 0.76 & 0.83 & 0.87 & 0.52 \\
\hline df & 1 & 1 & 1 & 1 & 1 & 1 & 1 \\
\hline$p$ & 0.45 & 0.55 & 0.03 & 0.38 & 0.36 & 0.90 & 0.47 \\
\hline \multicolumn{8}{|l|}{ Work status } \\
\hline Earning & $10(28.6)$ & 13(35.1) & $15(25.4)$ & $17(40.5)$ & $9(27.3)$ & $9(30)$ & $25(27.2)$ \\
\hline Not earning & $25(71.4)$ & $24(64.9)$ & $44(74.6)$ & $25(59.5)$ & $24(72.7)$ & $21(70)$ & $67(72.8)$ \\
\hline$x^{2}$ & 0.009 & 1.0 & 1.0 & 4.6 & 0.08 & 0.01 & 0.52 \\
\hline df & 1 & 1 & 1 & 1 & 1 & 1 & 1 \\
\hline $\mathbf{p}$ & 0.92 & 0.86 & 0.30 & 0.03 & 0.76 & 0.90 & 0.47 \\
\hline \multicolumn{8}{|l|}{$\begin{array}{l}\text { Relationship with } \\
\text { patients }\end{array}$} \\
\hline Close & $30(85.7)$ & $27(73.0)$ & $44(74.6)$ & $28(66.7)$ & $23(69.7)$ & $23(76.7)$ & $67(72.8)$ \\
\hline Not close & $5(14.3)$ & $10(27.0)$ & $15(25.4)$ & $14(33.3)$ & $10(30.3)$ & $7(23.3)$ & $25(27.2)$ \\
\hline$x^{2}$ & 4.0 & 1.0 & 0.03 & 2.06 & 0.47 & 0.16 & 1.47 \\
\hline df & 1 & 1 & 1 & 1 & 1 & 1 & 1 \\
\hline$p$ & 0.04 & 0.30 & 0.86 & 0.15 & 0.49 & 0.68 & 0.22 \\
\hline \multicolumn{8}{|l|}{ Duration of care } \\
\hline Up to 5 years & $12(34.3)$ & $18(48.6)$ & $32(54.2)$ & $21(50)$ & $20(60.6)$ & $18(60)$ & $50(54.3)$ \\
\hline 5 and more years & $23(65.7)$ & 19(51.4) & $27(45.8)$ & $21(50)$ & $13(39.4)$ & $12(40)$ & $42(45.7)$ \\
\hline$\chi^{2}$ & 8.7 & 0.73 & 0.00 & 0.52 & 0.84 & 0.59 & 0.02 \\
\hline df & 1 & 1 & 1 & 1 & 1 & 1 & 1 \\
\hline $\mathbf{p}$ & 0.003 & 0.39 & 0.98 & 0.47 & 0.35 & 0.43 & 0.86 \\
\hline \multicolumn{8}{|l|}{ Monthly income } \\
\hline Up to 10000 & $20(57.1)$ & 17(45.9) & $20(33.9)$ & $15(35.7)$ & $8(24.2)$ & $10(33.3)$ & $39(42.4)$ \\
\hline 10000 and more & $15(42.9)$ & $20(54.1)$ & $39(66.1)$ & 27964.3) & $25(75.8)$ & $20(66.7)$ & $53(57.6)$ \\
\hline$x^{2}$ & 4.7 & 0.25 & 4.8 & 1.50 & 7.0 & 1.56 & 0.09 \\
\hline df & 1 & 1 & 1 & 1 & 1 & 1 & 1 \\
\hline$p$ & 0.03 & 0.61 & 0.02 & 0.22 & 0.008 & 0.21 & 0.76 \\
\hline
\end{tabular}

respectively. These findings are comparable with different study worldwide. ${ }^{16,20,24,25}$

The study has some limitations. The participants were from specific geographical region so generalization of the result to other areas is difficult. Another limitation of the study was that the study participants included in the study were those who presented in the out patient department of government health care center so generalaization of the result to the community cannot be done.

\section{CONCLUSION}

Caregivers of psychiatric patients experience different kind of burden of care. Among the objective burden domains disruption of family leisure was the most frequently reported burden disruption of mental health of others was the least frequent reported burden. Our study also revealed age, sex, marital status, educational status working status, monthly income, duration of care relationship with the patients of the caregivers all are associated with 
different domains of family burdens. We recommend the strengthening of psychological and social support to reduce caregiving burden of the caregivers.

\section{REFERENCES}

1. Alliance FC. Fact sheet: Selected caregiver statistics. San Francisco, CA. 2012.

2. Ampalam P, Gunturu S, Padma V. A comparative study of caregiver burden in psychiatric illness and chronic medical illness. Indian J Psychiatry. 2012 Jul;54(3):239-43.

3. Shen GC, Snowden LR. Institutionalization of deinstitutionalization: a cross-national analysis of mental health system reform. Int J Ment Health Syst. 2014 Nov;8(1):47.

4. Treichel CA, Jardim VM, Kantorski LP, Neutzling AS, Oliveira MM, Coimbra VC et al. Minor psychiatric disorders and their associations in family caregivers of people with mental disorders. Cien Saude Colet. 2017;22(11):3567-78.

5. Son J, Erno A, Shea DG, Femia EE, Zarit SH, Stephens MA. The caregiver stress process and health outcomes. J Aging Health. 2007 Dec;19(6):871-87.

6. Kessler RC, Aguilar-Gaxiola S, Alonso J, Chatterji S, Lee S, Ormel J, et al. The global burden of mental disorders: an update from the WHO World Mental Health (WMH) surveys. Epidemiol Psichiatr Soc. 2009 Jan-Mar;18(1):23-33.

7. Graessel E, Berth H, Lichte T, Grau H. Subjective caregiver burden: validity of the 10-item short version of the Burden Scale for Family Caregivers BSFC-s. BMC Geriatr. 2014 Feb;14(1):23.

8. Cardoso L, Galera SA, Vieira MV. Caregiver and burden health care of patients discharged from psychiatric hospitalization. Acta Paul Enferm. 2012;25(4):517-23.

9. Chan SW. Global perspective of burden of family caregivers for persons with schizophrenia. Arch Psychiatr Nurs. 2011 Oct;25(5):339-49.

10. Souza AL, Guimarães RA, de Araújo Vilela $D$, de Assis RM, de Almeida Cavalcante Oliveira LM, Souza MR, et al. Factors associated with the burden of family caregivers of patients with mental disorders: a crosssectional study. BMC Psychiatry. 2017 Oct;17(1):353.

11. Navidian A, Bahari F. Burden experienced by family caregivers of patients with mental disorders. Pak J Psychol Res. 2008;23(1/2):19.

12. Darlami K, Ponnose R, Jose P. Caregiver's stress of psychiatric patients. ournal of Universal College of Medical Sciences. 2016;3(2):39-43.

13. Bhandari A, Marahatta K, Rana M, Ojha S, Regmi M. Caregiving Burden among Family Members of People with Mental Illness. Journal of Psychiatrist's Association of Nepal. 2017;4(1):36-42.

14. Sharma R, Sharma SC, Pradhan SN. Assessing Caregiver Burden in Caregivers of Patients with Schizophrenia and Bipolar Affective DisorderNepal. Health Res Counc. 2017 Sep-Dec;15(37):258-63.

\section{ACKNOWLEDGEMENTS}

I would like to thank all the patients, their family members and KOSHISH foundation.

15. Koujalgi SR, Patil SR. Family burden in patient with schizophrenia and depressive disorder: a comparative study. Indian journal of psychological medicine. 2013; 35(3):251-5. https://doi. org/10.4103/0253-7176.119475.

16. Lasebikan VO, Ayinde OO. Family Burden in Caregivers of Schizophrenia Patients: Prevalence and Socio-demographic Correlates. Indian J Psychol Med. 2013 Jan;35(1):60-6.

17. Thomas JK, Suresh Kumar PN, Verma AN, Sinha VK, Andrade C. Psychosocial dysfunction and family burden in schizophrenia and obsessive compulsive disorder. Indian J Psychiatry. 2004 Jul;46(3):238-43.

18. Chan SW, Yip B, Tso S, Cheng BS, Tam W. Evaluation of a psychoeducation program for Chinese clients with schizophrenia and their family caregivers. Patient education and counseling. 2009; 75(1):67-6. https://doi.org/10.1016/j.pec.2008.08.028.

19. Fallahi Khoshknab M, Sheikhona M, Rahgouy A, Rahgozar M, Sodagari F. The effects of group psychoeducational programme on family burden in caregivers of Iranian patients with schizophrenia. Journal of psychiatric and mental health nursing. 2014; 21(5):438-46.

20. Hidru TH, Osman MH, Lolokote S, Li X. Extent and pattern of burden of care and its associated factors among Eritrean families of persons living with schizophrenia: a cross-sectional study. BMJ Open. 2016 Sep;6(9):e012127.

21. Hailemariam KW. The psychological distress, subjective burden and affiliate stigma among caregivers of people with mental illness in Amanuel Specialized Mental Hospital. Am J Appl Psychol. 2015;4(2):35-49.

22. Ayalew M, Workicho A, Tesfaye E, Hailesilasie H, Abera M. Burden among caregivers of people with mental illness at Jimma University Medical Center, Southwest Ethiopia: a cross-sectional study. Ann Gen Psychiatry. 2019 Jun;18(1):10.

23. Naughton C, Bennett K, Feely J. Prevalence of chronic disease in the elderly based on a national pharmacy claims database. Age Ageing. 2006 Nov;35(6):633-6.

24. Yu Y, Liu ZW, Tang BW, Zhao M, Liu XG, Xiao SY. Reported family burden of schizophrenia patients in rural China. PLoS One. 2017 Jun;12(6):e0179425.

25. Walke SC, Chandrasekaran V, Mayya SS. Caregiver Burden among Caregivers of Mentally III Individuals and Their Coping Mechanisms. J Neurosci Rural Pract. 2018 Apr-Jun;9(2):180-5. 